\title{
Interactive comment on "Photochemical
} transformation of residential wood combustion emissions: dependence of organic aerosol composition on $\mathrm{OH}$ exposure" by Anni Hartikainen et al.

\section{Anni Hartikainen et al.}

anni.hartikainen@uef.fi

Received and published: 10 March 2020

We thank the reviewer for this thorough feedback, which has been very useful in improving the composition and preciseness of the manuscript. We provide point-by-point responses to the comments and questions in the attached supplement. Changes done to the original manuscript during revision are visible in a supplement of an additional comment in the manuscript discussion thread. 
https://www.atmos-chem-phys-discuss.net/acp-2019-1078/acp-2019-1078-AC1supplement.pdf

ACPD

Interactive comment on Atmos. Chem. Phys. Discuss., https://doi.org/10.5194/acp-2019-1078, 2019.

Interactive

comment 